\title{
SINKRONISASI FRAME PADA MODEM OFDM DALAM RENTANG FREKUENSI AUDIO
}

\author{
Yulia Fitri \\ Program Studi Fisika, FMIPA, Universitas Muhammadiyah Riau \\ Jl. KH Ahmad Dahlan No. 88 Sukajadi Pekanbaru \\ e-mail: yulia_fitri18@yahoo.com
}

\begin{abstract}
ABSTRAK
Orthogonal Frequency Division Multiplexing (OFDM) adalah sebuah teknik transmisi paralel menggunakan banyak frekuensi yang saling tegak lurus (orthogonal) sebagai carrier-nya. OFDM telah dikembangkan untuk berbagai aplikasi sistem telekomunikasi karena transmisi data berkecepatan tinggi dan efisiensi dalam pemakaian bandwidth. Namun, OFDM juga memiliki kelemahan terutama kesalahan dalam menentukan awal data sinyal. Pada penelitian ini, sinkronisasi frame modem OFDM didesain untuk menentukan awal data sinyal yang ditransmisikan dalam rentang frekuensi audio. Sinkronisasi frame ini menggunakan teknik cross correlation preamble. Sistem dimodelkan dan disimulasikan menggunakan software Matlab dan diimplemantasikan pada OMAP L137 TMS320C6747. Dari hasil simulasi, variasi frekuensi preamble tidak mempengaruhi performa sinkronisasi frame. Pada implementasi secara real time, sinkronisasi frame modem OFDM menghasilkan suara dan spektrum yang jelas pada frekuensi preamble lebih besar dari $250 \mathrm{~Hz}$.
\end{abstract}

Kata kunci: OFDM, preamble, sinkronisasi frame

\section{PENDAHULUAN}

OFDM merupakan sebuah teknik transmisi yang menggunakan banyak frekuensi subcarrier (multicarrier) yang saling tegak lurus (orthogonal). OFDM telah dikembangkan untuk berbagai aplikasi karena transmisi data berkecepatan tinggi dan efisiensi dalam pemakaian bandwidth [1]. Pada teknologi telekomunikasi, OFDM dijadikan sebagai standar Digital Audio Broadcast (DAB) [2] dan Digital Video Broadcast (DVB) $[3,4]$. Selain itu, OFDM diaplikasikan juga pada Terrestrial Integrated Services Digital Broadcasting (ISDB-T), Digital Subscriber Line (xDSL), sistem WLAN [5], Flash OFDM, Power Line Communication (PLC) dan pada komunikasi radio [6,7]. Salah satu tujuan dari penelitian ini adalah mendesain modem (modulasi demodulasi) OFDM pada rentang frekuensi audio dengan bandwidth $<3$ $\mathrm{KHz}$ [8]. Karena data ditransmisikan pada rentang frekuensi audio, maka modem yang didesain bersifat universal yang dapat diaplikasikan pada berbagai perangkat komunikasi. Selain itu, modem OFDM ini dapat mengirimkan data file, teks, gambar dan suara.
Dalam penelitian ini, modem OFDM diaplikasikan untuk pengiriman dan penerimaan suara.

Di sisi lain, teknik OFDM juga memiliki kelemahan terutama sensitivitas yang tinggi terhadap kesalahan sinkronisasi antara transmitter dan receiver. Kesalahan sinkronisasi diantaranya disebabkan oleh kesalahan menentukan starting point (awal data) sinyal OFDM untuk memulai operasi FFT, sehingga simbol akan overlap dan menimbulkan Inter Symbol Interference (ISI). Untuk mengatasi kesalahan sinkronisasi antara transmitter dan receiver pada modem OFDM, maka pada receiver harus ditambahkan sinkronisasi frame untuk menentukan start point sinyal OFDM. Pada penelitian ini akan fokus pada sinkronisasi frame untuk menentukan awal data dari sinyal OFDM, karena kesalahan sinkronisasi frame akan mempengaruhi semua simbol pada frame yang akan masuk ke FFT di receiver. Dalam beberapa dekade terakhir, banyak metode yang telah dikembangkan untuk sinkronisasi frame pada modem OFDM [9-14]. Pada penelitian ini, sinkronisasi frame didesain dengan 
menambahkan preamble sebagai awal data dari sinyal OFDM. Preamble yang digunakan berupa gelombang sinusoidal.

\section{METODOLOGI PENELITIAN}

\section{Sistem Modem OFDM}

OFDM adalah salah satu jenis dari multicarrier (FDM), memiliki efisiensi spektrum yang jauh lebih baik karena antara satu subcarrier dengan subcarrier lainnya saling orthogonal. OFDM pertama kali dikembangkan pada tahun 1960-an. Chang [1] memperkenalkan teknik modulasi multicarrier, kemudian Saltzberg [16] menganalisis performa Chang dan memperoleh kesimpulan bahwa untuk merancang transmisi multicarrier lebih difokuskan pada solusi untuk mengurangi overlap antara carrier yang bersebelahan. Pada tahun 1971, Weinstein dan Ebert [17] memberikan kontribusi yang besar pada OFDM. Mereka mengusulkan metode Dicrete Fourier Transform (DFT) untuk modulasi dan demodulasi sinyal. Pada OFDM overlap antara subcarrier-subcarrier diperbolehkan tanpa interferensi satu sama lain, karena masing-masing sudah saling orthogonal $[18,19]$. Persamaan sinyal OFDM secara matematika dapat dituliskan:

$$
y(k)=\frac{1}{N} \sum_{n=0}^{N-1} x(n) e^{\frac{j 2 \pi n k}{N}}
$$

Modem OFDM terdiri dari dua blok diagram transmitter dan receiver, blok diagram secara umum dapat dilihat pada Gambar 1. Deretan data yang akan ditransmisikan (data in) merupakan deretan bit-bit serial dari Analog to Digital Converter (ADC) yang dipetakan (mapper) menggunakan PSK atau QAM. Kemudian data dikonversikan ke dalam bentuk data paralel oleh serial to parallel convertion, sehingga bila bitrate semula adalah $R$ maka bitrate setiap jalur paralel adalah $R / N$ dimana $N$ adalah jumlah subcarrier.

$\mathrm{N}$-bit data paralel ini diaplikasikan ke dalam IFFT untuk membuat simbol OFDM. IFFT akan mengubah sinyal dari domain frekuensi kedalam sinyal domain waktu. Selanjutnya, sinyal dikonversi kembali ke dalam bentuk serial. WI ditambahkan untuk mengurangi ukuran sidelobe, karena sidelobe yang besar akan menimbulkan ISI [20]. Sedangkan CP ditambahkan untuk mempertahankan keortogonalitasan antarsubcarrier [21]. Sebelum sinyal ditransmisikan, sinyal dikonversi kembali menjadi sinyal analog oleh DAC (Digital to Analog Converter).

Pada bagian receiver dilakukan proses yang berkebalikan dengan proses dilakukan pada transmitter. Sinyal analog dikonversi kebentuk digital oleh ADC dan sinyal data serial yang diterima oleh receiver dikonversi terlebih dahulu ke dalam bentuk data paralel. Selanjutnya dengan FFT sinyal dalam domain waktu diubah kembali menjadi domain frekuensi. Sebelum sinyal didemapper, sinyal dikonversi kembali ke bentuk serial. Setelah demapper, sinyal digital dikonversi kembali menjadi sinyal analog dan akhirnya kembali menjadi deretan data awal.

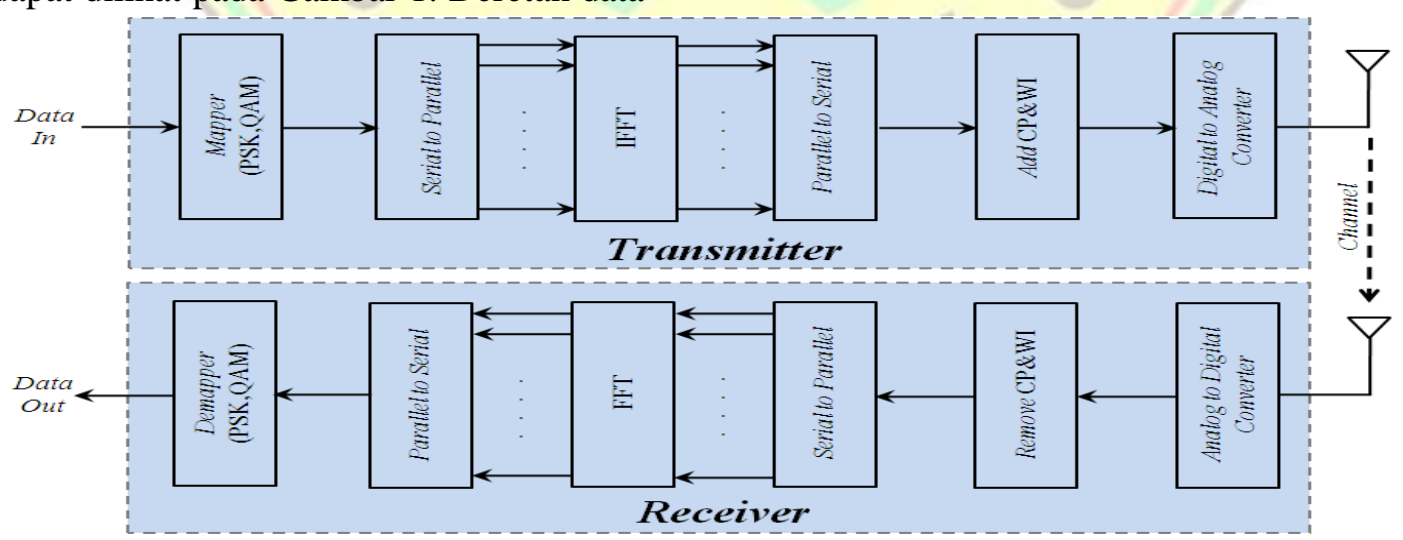

Gambar 1. Blok diagram modem OFDM.

\section{Sinkronisasi Frame}

Ketika teknologi OFDM diaplikasikan pada sistem telekomunikasi, sinkronisasi adalah hal yang sangat penting dalam membangun dan menjaga komunikasi antara transmitter dan receiver. Salah satunya, sinkronisasi frame 
dibutuhkan untuk menentukan awal data (starting point) dari sinyal yang ditransmisikan oleh transmitter modem OFDM. Blok receiver tidak dapat menentukan posisi awal data yang diterima dari transmitter. Jika awal data sinyal OFDM tidak diketahui, maka FFT akan menerima simbol overlap yang akan menimbulkan ISI.

Sinyal OFDM dapat didemodulasi, bila FFT di receiver hanya diisi data dari satu simbol OFDM saja. Jika data yang masuk ke FFT dari simbol overlap yang ditunjukkan Gambar 2, maka data OFDM akan rusak. Simbol OFDM tidak akan overlap bila awal data dari sinyal OFDM yang diterima oleh receiver dapat diketahui. Untuk mengatasi kesalahan sinkronisasi frame, maka ditambahkan $N$ sampel data yang diketahui sebagai awal data dari sinyal yang ditransmisikan oleh transmitter OFDM. $N$ sampel data yang diketahui tersebut dikenal dengan preamble. Preamble tidak membawa informasi, hanya untuk sinkronisasi frame di receiver. Sebelum sinyal OFDM ditransmisikan, preamble ditambahkan setelah blok IFFT di transmitter sebagai awal data.

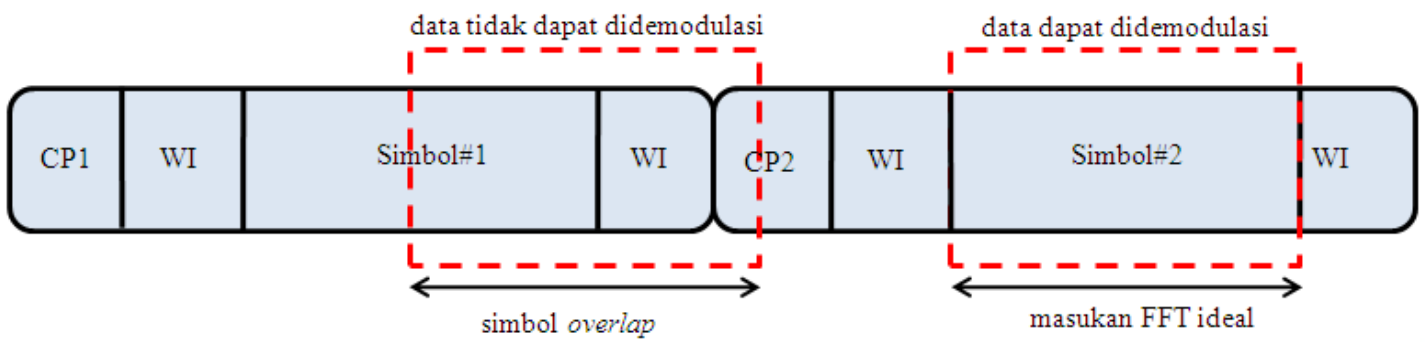

Gambar 2. Kenapa Sinkronisasi Frame Dibutuhkan.

Preamble yang ditambahkan sebagai awal data dari sinyal OFDM dilambangkan dengan $p(k)$ dan sinyal OFDM yang diterima oleh receiver dilambangkan dengan $r(k+n)$. Maka proses cross correlation antara preamble dengan sinyal OFDM yang diterima oleh receiver secara matematika dapat dituliskan sebagai berikut:

$$
C(n)=\sum_{k=0}^{N-1} r(k+n) p(k)
$$

Dimana $C(n)$ merupakan hasil cross correlation. Posisi maksimum dari cross correlation terjadi pada saat posisi preamble yang ditambahkan di transmitter sejajar dengan preamble yang diterima oleh receiver, yaitu saat $p(k)=r(k)$.

Cross correlation akan menghasilkan puncak, dimana dengan menentukan posisi puncak maksimum sinyal maka pergeseran sinyal dapat dihitung. Setelah pergeseran sinyal diketahui, maka awal data dari sinyal dapat ditentukan.

\section{HASIL DAN PEMBAHASAN Hasil Simulasi}

Pengujian performa dari sinkronisasi frame modem OFDM yang telah didesain menggunakan simulasi simulink Matlab. Pengujian performa modem OFDM dengan simulasi dipengaruhi oleh kanal Additive White Gaussian Noise (AWGN), frekuensi offset dan delay. Kesalahan menentukan awal data dari sinyal OFDM digunakan untuk menganalisa performa sinkronisasi frame modem OFDM.

Tabel 1 menunjukkan hasil simulasi sinkronisasi frame modem OFDM berdasarkan kesalahan menentukan ẩal \&lata pada algoritma sinkronisasi frame terhadap frekuensi preamble. Frekuensi preamble divariasikan dari $125 \mathrm{~Hz}$ sampai $1000 \mathrm{~Hz}$ dan jumlah delay yang ditambahkan pada simulasi adalah 17 sampel. Setiap frame sinyal OFDM berisi 72 sampel, karena ditambahkan delay maka awal data dari sinyal berada pada sampel ke 89 dan sampel ke17 bila awal data dideteksi pada frame berikutnya.

Pada tabel 1 juga terlihat bahwa algoritma sinkronisasi frame yang didesain dapat menentukan awal data dengan benar pada Signal to Noise Ratio (SNR) lebih besar dari $15 \mathrm{~dB}$. Variasi frekuensi preamble tidak mempengaruhi performa dari sinkronisasi frame, dimana semua frekuensi preamble yang divariasikan dapat bekerja dengan baik pada SNR yang sama. 
Tabel 1. Kesalahan menentukan awal data terhadap variasi frekuensi preamble

\begin{tabular}{||c|c|c|c|c||}
\hline \multirow{2}{*}{$\begin{array}{c}\text { Frekuensi } \\
\text { Preamble }(\mathbf{H z})\end{array}$} & \multicolumn{4}{|c||}{ SNR } \\
\cline { 2 - 5 } & $\mathbf{0}$ & $\mathbf{5}$ & $\mathbf{1 0}$ & $\mathbf{1 5}$ \\
\hline \hline 125 & 84 & 92 & 95 & 89 \\
\hline 250 & 98 & 100 & 73 & 89 \\
\hline 500 & 93 & 83 & 75 & 89 \\
\hline 750 & 96 & 129 & 80 & 89 \\
\hline 1000 & 94 & 99 & 85 & 89 \\
\hline
\end{tabular}

Untuk menentukan besarnya pergeseran sinyal yang diakibatkan oleh delay selama transmisi antara transmitter dan receiver, maka dihitung puncak maksimum dari hasil cross correlation preamble. Hasil cross correlation pada berbagai frekuensi preamble menghasilkan puncak maksimum yang sama, karena amplitudo preamble yang dikirimkan sama. Hal inilah yang menyebabkan variasi frekuensi preamble tidak mempengaruhi performa sinkronisasi frame modem OFDM.

\section{Hasil implementasi}

Pada implementasi modem OFDM secara real time, frekuensi preamble yang digunakan untuk sinkronisasi frame divariasikan yaitu $125 \mathrm{~Hz}, 250$ $\mathrm{Hz}, 500 \mathrm{~Hz}, 750 \mathrm{~Hz}$ dan $1 \mathrm{KHz}$. Frekuensi preamble divariasikan untuk melihat performa algoritma sinkronisasi frame yang telah didesain secara real time. Dengan menvariasikan frekuensi preamble dapat diketahui frekuensi minimum yang bisa digunakan untuk menentukan awal data sinyal OFDM pada sinkronisasi frame. Hasil implementasi modem OFDM untuk frekuensi preamble $125 \mathrm{~Hz}$, suara dan spektrum hasil implementasi kurang jelas. Sedangkan pada frekuensi preamble besar dari $250 \mathrm{~Hz}$, menghasilkan suara dan spektrum yang jelas.

Hasil implementasi secara real time ini berbeda dengan hasil simulasi, dimana pada simulasi frekuensi preamble tidak mempengaruhi performa dari sinkronisasi frame modem OFDM yang didesain. Kurang jelasnya suara yang dihasilkan pada frekuensi preamble $125 \mathrm{~Hz}$, diperkirakan karena pengaruh frekuensi offset yang lebih besar terhadap frekuensi yang rendah. Pada frekuensi preamble lebih besar dari $250 \mathrm{~Hz}$, frekuensi offset hanya memberikan pengaruh yang kecil sehingga tidak merusak performa sinkronisasi frame modem OFDM.

\section{KESIMPULAN}

Sinkronisasi frame pada modem OFDM telah didesain dan diimplementasikan pada OMAP L137 TMS320C6747. Di dalam penelitian ini, sistem modem OFDM didesain dan ditransmisikan pada rentang frekuensi audio dengan bandwidth $<3 \mathrm{KHz}$. Sinkronisasi frame didesain untuk menentukan awal data sinyal OFDM menggunakan preamble berupa gelombang sinusoidal yang ditambahkan sebagai awal data sinyal OFDM. Untuk menganalisa performa sinkronisasi frame, maka divariasikan frekuensi preamble dan frekuensi offset.

Dari hasil analisa simulasi menunjukkan bahwa variasi frekuensi preamble tidak mempengaruhi performa sinkronisasi frame. Hal ini terlihat dari awal data sinyal OFDM dapat ditentukan

dengan benar pada SNR yang sama. Selain itu, sinkronisasi frame masih dapat bekerja dengan baik pada pengaruh frekuensi offset yang rendah.

Pada implementasi secara real time, sinkronisasi frame modem OFDM menghasilkan suara dan spektrum yang jelas pada frekuensi preamble lebih besar dari $250 \mathrm{~Hz}$.

\section{DAFTAR PUSTAKA}

[1] Chang, R.W., "Synthesis of band-limited orthogonal signals formultichannel data transmission," Bell Syst. Tech. J, vol. 45, pp. 1775-1796, December 1966.

[2] Plenge G., "DAB - a new radio broadcasting system - state of development and ways for its introduction," Rundfunktech. Mitt., vol. 35, no. 2, 1991.

[3] Sari H., Karam G., and Jeanclaude I., "Transmission techniques for digital terrestrial TV broadcasting," IEEE Communications Magazine, pp. 100-109, February 1995.

[4] ETSI, "Digital video Broadcasting (DVB)," 1.1.2 ed., EN 300 744, August 1997.

[5] IEEE Std. 802.11a., "Part 11: Wireless LAN Media Access Control and Physical Layer Specifications." IEEE SA-Standards Board. June 12, 2003. 
[6] C. Sonntag, “Orthogonal Frequency Division Multiplexing (OFDM) Implementation as Part of a Software Defined Radio (SDR) Environtment," University of Stellenbosch, South Africa, 2005.

[7] L. Vercimak dan K. Weyeneth," Software Defined Radio," Bradley University, 2006.

[8] Mcloughlin I., "Applied speech and audio processing," Cambridge University Press, 2009.

[9] Van de Beek J.-J., Sandell M., Isaksson M., and Börjesson P. O., "Low-complex frame synchronization in OFDM systems," in Proceedings of IEEE International Conference on Universal Personal Communication (ICUPC, 1995), pp. 982 986, Tokyo, Japan, November 1995.

[10]Schmidl T. M. and Cox D. C., "Robust frequency and timing synchronization for OFDM," IEEE Trans. on Commun., vol. 45, no. 12, pp. 1613-1621, December 1997.

[11]Minn H., Bhargava V., and Letaief K., “A robust timing and frequency synchronization for OFDM systems," IEEE Trans. on Commun., vol. 2, pp. 822-839, 2003.

[12]Williams C., Beach M. A., and McLaughlin S., "Robust OFDM timing synchronisation," Electron. Lett., vol. 41, pp. 751-752, June 2005.

[13] Feng J., Mei S., Da Guo, Jun-de S., "OFDM frame synchronization based on energy difference of the received preamble," The
Jounal of China Universities of Post and Telecommunication, Vo. 14, March 2007.

[14] Eyadeh A., "Frame synchronization symbols for an OFDM system," International Journal of Communication, Vol. 2, 2008.

[15] Texas Instruments/Spectrum Digital, "TMS320C6747 technical reference," 511345-0001 Rev. A, November 2008.

[16] Saltzberg, B. R., "Performance of an efficient parallel data transmission system," IEEE Trans. Comm. Technol., vol. 15, December 1967.

[17] Weinstein, B., and Ebert P., "Data transmission by frequency division multiplexing using the discrete Fourier transform," IEEE Trans. Comm. Technol., vol. 19, no. 5, October 1971.

[18] Edfors, O., et al., "An Introduction to Orthogonal Frequency-Division Multiplexing," Research Report TULEA, Division of Signal Processing, Luleå University of Technology, 1996.

[19] Van de Beek J. J., et al., " Orthogonal frequency division multiplexing (OFDM)," The Internation Union of Radio Science (URSI), Lulea University of technology, 2002

[20] Prasad, Ramjee., OFDM for Wireless Communication Systems, Artech House, 2004.

[21] Heiskala J., Terry J., OFDM Wireless LANS: A Theoretical and Practical Guide, SAMS Publication, 2002. 